\title{
Environment-Behavior Research and the Practice of Architecture: Paradigms and Paradoxes
}

\author{
Ranjith Dayaratne
}

\begin{abstract}
Practice of architecture relies heavily upon "architecture as an art paradigm" and nurtures its aesthetic theory base as the fundamental postulate upon which design is founded. In contrast, Environment-Behaviour' research as a discipline that has emerged from within the academic field of architecture examining the interface between environments and people has evolved into a major scientific endeavor conducting research and teaching 'advance theories of architecture, environments and people'. However, the influence of environment-behaviour research on the real practice of architecture seems surprisingly modest. This is evident in the many discourses on contemporany buildings acclaimed in architecture magazines, design tutoring sessions as well as designjuries both in schools as well as in international architectural competitions. This paper examines the bi-polarity of theory versus practice that exists within the field of architecture manifested very clearly in the way the environment-behavior research and architectural practices have evolved.
\end{abstract}

\section{Introduction .}

Architecture has traditionally been a practice that is aligned with the arts and thus inclined towards 'aesthetics' as its theory base. The statements that architecture is primarily an art and that architects act more like artists has been popular among both students of architecture and practicing architects alike since the times of Inigo Jones and continue to be so. Within this architecture as an art paradigm however, there has been a major focus upon 'people' from the time of the Bauhaus to date to the extent that teaching of psychology and social sciences have been considered major inputs to architectural education. Since 1970 s and particularly since the failures in mass housing and modern architecture, this paradigm has faced severe criticisms, challenges and indeed altemative theories that a number of new disciplines have emerged both within the main stream architecture discipline as well as the social sciences that are concerned with the human settlements, societies and people.

Variously known as Environment-Behaviour research, Environmental Psychology, and Man-Environment Studies, these offer knowledge that challenges the validity of the 'architecture as art' paradigm and help advance the theory base of the practice of architecture. The new theories have come from two directions addressing two different concerns in their respective fields: from the mainstream design professions of architecture and planning, and from the social sciences such as psychology and sociology. In the former, the concerns have been about understanding the impact the designed environments have upon people so that the design activity can be improved and in the latter, the concerns have been upon understanding the role of the environment on the behavior of people so that their behaviour can be well understood.

\section{An Increasing Focus on People in Architecture}

One of the stated primary intentions in architecture has been that of designing for people and their social psychological and cultural needs: In other words, environments, which provide opportunities for making homes and places. As Kraik (1970) has pointed out, architects have always claimed to be designing for people and thus to be interested in designing environments that can uplift the spirit and enhance their sense of well-being. However, there has been growing criticisms since 1970s against most modern builtenvironments which accuse the architects of having alienated people from their own settings (MacEvan, 1974) particularly in the area of housing (Mikellides, 1980) Dwellers, social scientists, politicians, as well as architects themselves have noted that professional's involvement in designing for people have been far from what was anticipated and desired. As Lang (1974) wrote 'there has been a tremendous gap between the architects intentions and their achievements'.

Many reasons have been attributed to this situation and Lang (1974) discusses three specific reasons to be at the core of this gap. As he notes,

- The nature of the client is changing to growing heterogeneity: Architects no longer design for people like themselves; people with similar needs, values and attitudes.

- Peoples' shelter needs have shifted from those related to physiology and security towards higher order needs of self-esteem, identity, etc. 
- The profession has been reluctant in the reconsideration of traditional principles and processes of design.

Perin (1974) and Mitchell (1974) add more to these reasons and argue that,

- Most architects believe that architecture is by and large an atheoretical discipline.

- Traditional design approaches focus on the relationship of the architect to the artifact, rather than people to their places.

Indeed most saw these as a problem of architectural theory. As Lang pointed out,

"One of the reasons for this situation is related to the nature of architectural theory: A detailed knowledge of human behaviour, aspirations and values has not played a prominent role in the shaping of either architectural theory or buildings. This must change" (Lang, 1974:3)

\section{An Increasing Recognition of the Role of Environment in Social Sciences}

It is interesting to note that the demands for accommodating social concerns in architecture are paralleled by the demands made in psychology in accommodating the built-environment as a variable in their studies. Indeed in social sciences and in psychology in particular, there had been a notable absence of the facets of the built-environment taken as a component of their examinations of people's behaviour either within the traditions of experimental laboratories or in the real world.

As Canter (1983) points out, "when psychologists in general and social psychologists in particular embraced the experimental laboratory approach, they adopted with it the view that the laboratory is a neutral setting playing no part in the processes to be studied". In fact, these assumed that the psychology of the individuals studied in the areas of social psychology and other disciplines had no physical environmental variables affecting their social and psychological facets".

Social sciences such as psychology and sociology before 1980 s had suffered from their inability to accommodate the role of the environment in their formulations. Even when they were considered, they were often given only a minimal role in the issues studied. Margulis (1980) for example in reviewing learning theory, personality theory, social psychological theory and perceptual theory noted that "in general, the objective environment in psychological theory has a null status" and that even perceptual theory that examines visual perception of the environment presented a view of perception which "mirrored the internal world of values". As Canter (1983) pointed out, psychologists as a rule have favored points of view that stress what is inside the head, not what the head was inside"
So it was against this background that the social sciences began in early 1970 s to focus increasingly upon the environment as a major facet that influences psychology and human behaviour.

\section{Emergence of New Orientations and Disciplines And the Creation of Architectural Theory}

The outcome of these understandings and recognition of the significance of having a detailed knowledge of people for design professions and the role of the environment for understanding the social and psychological processes have manifested in two different ways. On the one hand, these have led to the emergence of new disciplines crossing the traditional boundaries of architecture and social sciences and on the other hand, they have also led to re-orientations of focus within the disciplines in which the questions were raised. Thus in the field of architecture, a new emphasis emerged in taking on board the people and the likely impacts architecture have on them while new academic branches of inquiry such as the environment-behaviour studies, Man-Environment studies etc. emerged. In the field of psychology in particular, a field referred to as Environmental Psychology emerged now being reformulated as Environmental Social Psychology (Canter, 1989). In the other branches of psychology, an increasing concern for environments has surfaced.

What concerns us most however is the question of architectural theory; the set of principles that we employ in the conception and creation of buildings. Do the architect-practitioners who design buildings and get them built employ theories that have come from these new fields. Have the theories of Architecture taken any new orientations in the light of these new disciplines that have emerged? Indeed it is fair to expect that this is what was expected and it has now taken place. For example in writing a book on the role of the behavioural sciences in creating architectural theory, Lang wrote "architects, landscape architects and urban designers have long been burrowing ideas from the behavioral sciences and from speculative philosophies on the nature of human acting and thinking. They have done this, however, without ever developing a coherent body of knowledge about the built-environment and what it affords people or about design praxis: There has been little coherent architectural theory. This is changing" (Lang, 1974). Three decades later the question is whether it has really changed.

It is undeniable that there exists now a wide array of joumals, books and other publications on the researches in to the relations between people and their physical settings. At least four international associations exist (EDRA, IAPS, MERA and PAPER) ${ }^{2}$ focused on the advancement of research in this field. The most notable observation that can be made however is that almost all.new disciplines and all such associations are multidisciplinary. While the richness of knowledge that may 
surface form such multi-disciplinary involvement cannot be under estimated, it has also so happened that as a result, architecture has become 'one of the disciplines' among many and therefore the emphasis of research are diverse and have moved away from design. In other words, the issue of design as an intervention in the people- environment relations and how all this new knowledge may be "applied" has failed to acquire the focus of these new examinations.

Rapoport (1994) points out the complexity of this situation. He wrote "One of the strengths of EnvironmentBehaviour Studies (EBS), its interdisciplinary nature since it's beginning in the 1960 s is also one of the problems with the field. It leads to fragmentation so that one's work appears in many different places- the journals of different disciplines, in a variety of other formats, and in a variety of countries...the result is a multiplicity of non-overlapping domains, sources and reading publics". Indeed this implies that this variety of presence makes it difficult to assimilate the body of knowledge and thus cross-fertilizations have also become difficult. In fact, from the position of "creating architectural theory" as Lang anticipated and claimed to have begun to change, assimilation of knowledge from these new examinations and formulating any coherent architectural theory has not been easy if not almost impossible.

There are two aspects the examination of which will throw light on these new developments. On the one hand, there have been a number of changing paradigms within these new disciplines on the relations between people and their physical settings. On the other hand, a wide range of new concepts and aspects of these relations have been discovered and theories have been comprehensively advanced on these particular aspects employing particular methodologies.

\section{Changing Paradigms on People-Environment Relations}

\section{a. Environmental Determinism (Architectural Determinism)}

Many theories have emerged based upon a notion that the environments have determinate impacts upon people. In this view, popularly known as the 'deterministic paradigm", architecture and built-environments are considered major and the people are considered as helpless entities subject to the conditions imposed by the environments. As Canter (1985) points out, "people are seen as being so constituted that unitary, relatively simple aspects of our surroundings have specific consequences for what we think feel and do". Porteous (1977) defines determinism as a concept that asserts environment as a dictator directing people's actions in one direction rather than another. Physical environment is believed to 'determine' human behaviour and therefore as having a definite causal relationship. Broady (1968) points out that this is the view that 'good physical environments' will necessarily produce 'good social effects'.

As Broady writes, "it implies a one way process in which the physical environment is the independent and the human behaviour the dependant variable. It suggests that those people for whom architects and planners create their designs are simply moulded by the environments provided for them". The idea had an overwhelming effect on design practice under the notion "user requirements" and designs aimed at producing a tight fit between the users' needs and architecture created. Architectural determinism captured the popular imagination of architects and affected both practice and education. On the one hand, it elevated the status of the professional and raised the assumption that the practices of professionals such as architects and planners moulded the environments and the society. It offered a sense of superiority and control to the professional and at the same time, with its simplistic relationship evaded the complexity of the interactions between people and their physical settings. Montgomery (1977) points out that "a widely understood and generally accepted model emerged. It connected the social and behavioural sciences in the following way: Social research $\rightarrow$ data on environmental needs, effects and fit $\rightarrow$ necessary input to do correct and effective design".

\section{Environment (Architecture)}

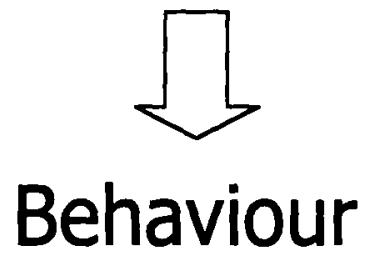

Fig. 1. A Model of the Deterministic Paradigm

Immersed in this paradigm, many researchers have gone on to examine the impact of colour, the shape of a room or a size of a room ceiling angle, furniture arrangement or a particular attribute that may have particular implications for people (Canter, 1972), Indeed some architects following the deterministic stand now claim that if we know the effect of the attributes of an environmental quality and the resulting behaviour of people in response to that quality then we may work backwards to establish the attributes to be created in architecture (Sri Nammuni, 1991a, 1991b, 1991c,1992) in anticipation of a desired behaviour. 


\section{The Interractionist Paradigm}

The recognition that the relations between people and physical settings is not as direct and causal as the deterministic paradigm suggested has led to changes to this model, adding meaning and other attributes as intermediary factors interacting between people and their environments. Those who focused on the idea of meaning proposed that the meanings people assign to the environments mediate the effects the environments have for people and that such meanings are both given and modified by the people themselves.

Interractionist view and the sets of theories which are derived from it proposes that some aspects of the individual are brought to bear to change the nature of the influences that the surroundings have. They suggest that physical stimuli do not have general consequences for all people but vary dramatically from one person to another.

In fact, Kurt Lewin constructed a theory that is explained by the formula $B=f(P . E)$ to emulate the correlates of these theories. Behaviour is considered as a function of some attributes of the person and some attributes of the environment and their interaction in a particular way. These theories led to the examination of personality characteristics and their variations as a major aspect of their sensitivity and reaction to their environment.

Interractionism helped dilute the deterministic attitude and created a significant inclusion of the aspects of meaning in architecture. Semiotics and non-verbal communication approaches have been examined and a notable body of knowledge about how people assign meanings and interpret them in the process of acting upon those cues has enabled a clearer understanding of the interactions between people and their physical settings. Most important change however is the perception of this process as a reciprocal one than a one-way process that quickly evolves into a transactionist paradigm.

\section{ENVIRONMENT}

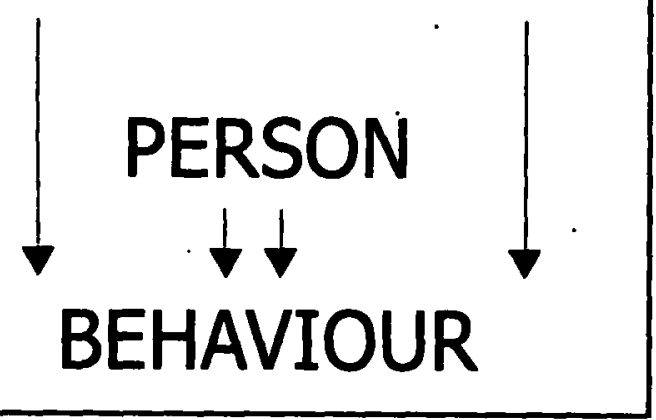

Fig 2. A Model of the Interractionist Paradigm

\section{The Trasactionist Paradigm}

The Trasactionist Paradigm may well be illustrated with reference to a well-known story about one of the great architects of the $20^{\text {th }}$ century. Louis Khan is said to have re-visited the biology laboratories he designed only to discover that the huge windows that were such a significant element of the architecture created had been covered with brown paper by the biologists who occupied the building.

The point was that glass admitted far too much light for the biology experiments and that the users decided themselves to act upon the environment and modify them to suit their particular situations. Khan is said to have been horrified by this 'abuse' of his architecture and have accused the users for having been totally unsympathetic to the architecture he created.

As Canter (1985) points out, "the influence of people on their environments may be much more than mere modifications of the impact of those surroundings. People may completely change the nature of their surroundings and the meanings they have. If not by brown paper then by what they do there. If not by what they do, then by the way they think of the physical setting".

In fact, Transactionist paradigm emphasizes on the reciprocal nature of the relations between people and their environments. It takes into account the people, the environment and their social and psychological contexts and argues that as much as the environments have implications for people, the very presence of the people themselves bring implications for the environments. It is suggested that there is no direct causal relationship between people and their physical settings but the key to understanding these relationships involve understanding the conceptualizations people have of their environments and their social contexts.

Indeed, in this model, people and environments are not considered as static separate entities one having an impact upon the other or interacting with each other, but as continuously evolving organisms having components in each other. Transactionism proposes an evolving dialectic between human actions and the contexts in which those human actions occur. As Canter (1985) says "to distinguish between action and context and to assume that past relationships between them have the same function in the present is illogical because both the organism and the environments are evolving together". 


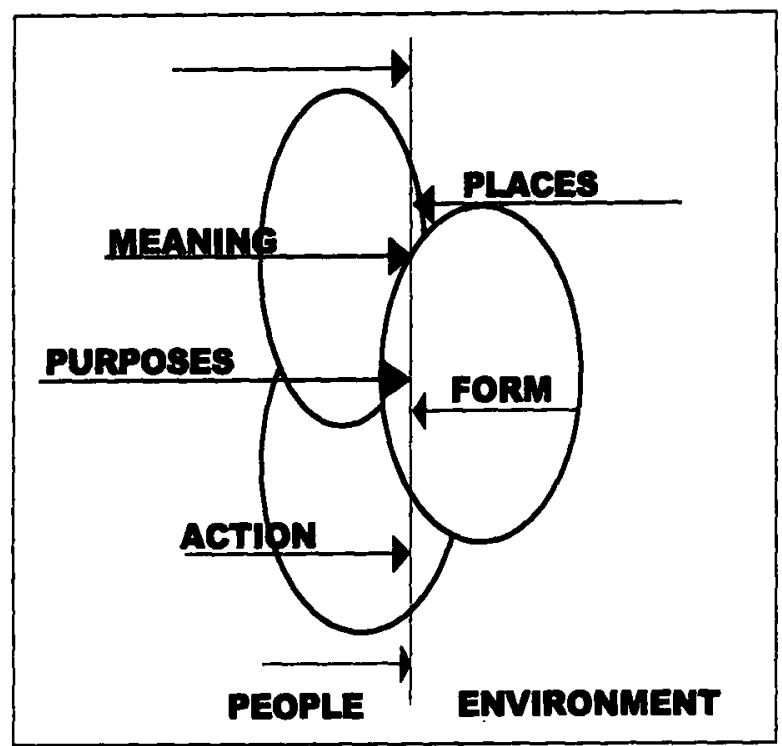

Fig 3. A Model of the Transactionist Paradigm (Canter 1977)

\section{Emerging Vlews, Concepts and Formulation of Theory}

Within these different paradigms, a number of concepts have come to dominate the environment-behaviour and environmental psychology discourses and thus mark the lines of inquiry in these new fields. Moreover, the conceptual bases have stemmed from a number of 'views' of the man-environment interface and the methods adopted in divulging them.

\section{USER}

\begin{tabular}{|ll|}
\hline - & \multicolumn{1}{c|}{ Lilestyles } \\
- & Concepluatizations \\
- & Pehavious \\
- & Cognition \\
- & Activities \\
- & Nevaluations \\
- & Motivations \\
- & Puposeses \\
- & Design \\
- & Use of space \\
- & Personalization \\
\hline
\end{tabular}

has become dominant. However, this view is not seen as central to the environment-behaviour research but Environmental Design (Alexander, 1977,1979; Dovey, 1985) and Social and Humanistic Geography Architecture (Schultz, 1980) and Environmental Psychology (Canter 1977). However there are distinct differences in the approaches to the understanding and articulation of 'theories of place' among these disciplines. While Architecture, Social and Humanistic Geography and Environmental Design explore the idea of place based on phenomenological approaches, Environmental Psychology takes a largely positivistic position in its exploration.

Most notable among the concepts articulated within the view of people as 'users' in environment-behaviour research can be classified on the basis of the aspects they relate to and can be noted as follows.

\section{Methods of Examinations}

Environment-Behaviour Research has also brought together refined methods of examinations burrowed from social sciences and have developed them to suit the focus of the inquiries. As can be seen from the above, the focus has ranged from examining the aspects of people, and aspects of the environments to the aspects of the interface and there is no doubt that the overiaps have always been included. However, it is also noteworthy that as argued earlier in this paper, the relation to the design process, practice of architecture

\section{INTERFACE}

\begin{tabular}{|c|}
\hline $\begin{array}{l}\text { - Images and schemata } \\
\text { - } \quad \text { Built -form } \\
\text { - Symbollsm } \\
\text { - Meaning } \\
\text { - Culture } \\
\text { - Tradition } \\
\text { - Territoria lity } \\
\text { - Pivacy } \\
\text { - Identity } \\
\text { - Emvironmental Stress } \\
\text { - Crowding } \\
\text { - Semioties } \\
\text { - } \\
\text { - }\end{array}$ \\
\hline
\end{tabular}

Fig. 4 : Aspects of EB Research

\section{ENVIRONMENTS}

\begin{tabular}{|ll|}
\hline - & Sellings \\
- & Precodents \\
- & Dernacular \\
- & Nature \\
- Spontaneous \\
- & Spatial quality \\
- Env. Cues \\
- & Orvinanisation \\
- & flexbility \\
- & adaptability \\
- & open ondedness \\
\hline
\end{tabular}

The most notable among them argue for the view of the environment as a 'system of settings in which a system of activitles' (Rapoport, 1990) can be obsenved. In fact, the field of environment-behaviour largely subscribes to this view as its dominant theoretical postulate, in which people are seen and referred to as 'users'.

This view is comparable with an altemative that presents this interface in terms of "situatlons arising from the habltation of people generating a pattern of events in patterns of places" in which the idea of 'place' and therefore the construction of a theory of architecture have been undeclared but assumed intentions.

The methodologies themselves show that the research in the field has so far been bent on the discovery of facts, data and information required for the task of design. How these data may indeed be injected into the design process in the real practice has however received comparatively little focus and therefore remains a major void that has created the divergence of the two areas of activity: research and design. 
The methodologies adopted and advocated in pursuing the discovery of design relevant data and facts can be classified as being focused either towards the people or the environments, as follows.

\begin{tabular}{ll|}
\hline - & Questionnaires, \\
- & Enteniews, \\
- & Experimental laboratories \\
- & Exaliy reaction analysis \\
- & Pupilary dilation \\
- & Galvanometer \\
\hline
\end{tabular}

\begin{tabular}{ll|}
\hline - & Participatory observation, \\
- & Von - participatory observation \\
- & Time lapse photography \\
- & Pholographic analysis \\
- Mapping \\
- Examining records, writings and \\
- other Media \\
Content analysis \\
\hline
\end{tabular}

Fig. 5 : Mothodologies of EB Research

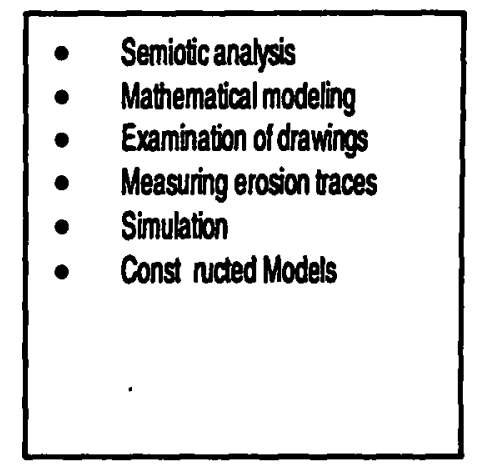

- Semiotic analysis

Mathematical modeling

Examination of drawings

Measuring erosion traces

- Const nucted Models

\section{Assimilation of Principles of Design and their Application}

The vast body of knowledge developed within the field of environment-behaviour research has undeniably helped the construction of theories that enable the understanding of these issues. There is also no doubt that more and more research continues to refine this knowledge base. For example, we now understand how differences exist between people's perceptions and professionals' perceptions, and why these differences exist. Theories that explain how personalization of designed environments takes place, how a sense of identity may arise from the built-environments or how privacy is articulated in specific situations are now known, however inadequate they may be. When it comes to the application of this knowledge to the conception and creation of buildings and absorption in to the design process however, major obstacles seem to appear. On the one hand, there is no coherence of such theories available in the way that they can be linked to the popular design processes. On the other, many of the data and information as same as the theories are far too general to be directly applied to a specific situation a designer has in hand.

Moreover, much of this research also assumes that once information and data are available, they will enable 'good' design to be done, good being equated most often to a tight fit between needs and wants of people and their aspirations and the attributes of the created environments. But it is undeniable that we live in a continuously changing world and that most things are in a state of flux, including the needs, wants and aspirations as same as contexts such as the social, cultural and political ones. Take the case of a design of a house for a family about whom let us assume that all information is generated using environment-behaviour' research, and that a 'good design' befitting these have been made. Construction of a house will take some time, and by the time a house is built, the family has changed. At the least, all members would have grown older, and that itself would have changed their aspirations and needs among many other things. Moreover a house built-for a family will pass over to another generation and/or to other families whose needs may be different. Thus the issue of 'tight-fit' falls apart and a loose fit is suggested. EBS has examined open-endedness, flexibility and other concepts that may help enable such approaches but the fact remains that 'all information required' to resolve all complexities of design can never be found and that the very 'design process' is fraught with the inability to transfer, non environmental data into creating spaces and environments.

A major area in which this seems demonstrably at odds is in the area of housing particularly in the developing countries. Research in squatter settlements can divulge the needs and aspirations of people, affordability, images and conceptions and preferences etc, if only finance is available to do so. Even if such finances were available and that such information were found, designed environments will only provide for the needs of the 'squatters' from whom the data may have been derived. Once the new housing is provided and that, the squatters have acquired new social status, together with new amenities and different environments, they will enter a different world in which different sets of needs aspirations and preferences will become visible. More over, it is almost impossible to know in the design of such environments, who exactly the 'users' will be before a housing estate is designed. Most often houses will have to be designed for 'imaginary' users about whom more general 'typologies' are available rather than specific information such as programs statistics and any other profiles. In this context, Hamdi (1992) argues that "we need methods for designing without detailed programs, a way of making plans without the preponderance of planning and social surveying".

In other words, it seems that despite the fact that Environment-Behaviour research has generated a diverse and vast amount of knowledge on issues on the interface between people and environments, they remain either unapplied in architectural practice or unapplicable in the design processes adopted in practice. One of the major reasons for this has indeed been the nature of 
design and the design process which despite numerous attempts to 'demystify' (Lawson, 1980) or streamlined to a method (Jones, 1973; Alexander,1964, 1977) remain for most architects, an intuitive process.

\section{Design Processes in the Practice of Architecture}

Indeed, in the practice of architecture, unlike in the research disciplines, these issues are taken rather more lightly. Most often than not, information and data are not available and there is hardly a time or capacity to create such knowledge particular to the situations at hand. Programs or briefs for buildings are mere lists of spaces required with floor areas and specific relations among them if they are known. The clients are unable to provide exacting requirements and the role of producing briefs lie in the hands of the designers, but neither finances nor time is available to the designers to carry out comprehensive research on other more significant aspects prior to the commencement of design activities. Interviews with clients may be held and questionnaires of user needs may be carried out occasionally but in a loose fashion and the findings of such research remain general and interpreted on personally bias ways with hardly rigorous scientific basis. 'General' guidelines that provide standards help articulate the briefs to some extent but there is a serious doubt if such standards fulfill the requirements posed by the complexity of man environment interfaces of the given situations. Cultural variations, situational differences and contextual specificities exist that make the use of any generalized guidelines loosely relevant. Most often, quantitative data on the sites, the users and the organizations and institutions to be housed in buildings are known to a reasonably accurate degree but qualitative information is hard to come by and difficult to be assimilated.

\section{Intritive Design Methodologies}

Moreover, there are hardly any design methodologies that ensure the synthesis of such information to coherent spatial ideas, which can be tested as being absolutely right or wrong. Instead, what most designers would employ is what is known as 'intuitive processes' to conceptualise what are popularly referred to as 'design concepts' that are based more upon individual philosophies (minimalism, deconstructivism, modernism etc.) and orientations and the nature of understanding the architects can bring to the situation. Neither the idea of the 'design concept' nor the way in which they articulate the designed environments are clear. While different designers would develop extremely different solutions to the same set of issues, which in their own assessments are 'right', they are hardly evaluated on the basis of criteria and issues divulged in environment-behaviour research. Design Juries can only offer value judgments made upon individual understandings rather than objective evaluations based on scientific theories. In fact, this diversity of solutions and the variety of perceptions is considered the most significant value in design that enables the 'creativity' of the designers to play a major role in the conception of designed environments. Undeniably the model of conceptions, practices and evaluations of design continue to remain deeply anchored within the realm of the aesthetic theories and practices.

\section{Poetics of Space as a Basis}

On the other hand, the celebrated work of designers point the progression of design practice in a different direction from what the environment-behaviour researchers have toiled for and have advocated to be adopted. A brief survey of master architects recognized and celebrated in the contemporary society across many cultures show that values and appreciations of architectural design hinge upon the quality of the 'poetics of space' rather than an environmentbehaviour fit. The process adopted by the designers and those advocated by the researchers seem to be indeed at the two ends of the spectrum. There is the belief that the 'facts' generated by research can hardly be transformed into 'making poetic space'. As the renowned architect of Sri Lanka Geoffery Bawa (1993) has very simply put it, "The worst addiction of modern architects is to design mentally rather than spatially" a criticism about the application of facts rather than insights.

In fact, neither the 'theory of architecture' as a subject taught in schools of architecture, nor the books published in this field make any reference to 'environment-behaviour research, their findings or the theories advanced in these new disciplines. More than three decades since the founding of these new disciplines, theory of architecture remains locked in to the discussions of 'isms' ranging from classicism, modernism, expressionism post modernism and minimalism etc. as their philosophical base upon which the ideas and concepts are constructed advocating its unstinted allegiance to the naturally evolving aesthetic theory base. In contrast, environment-behaviour theories remain as an entity on its own, taught separately and advanced often remotely related to the actual design practice.

\section{Valued Architecture}

Indeed, the profession draws its inspiration from the precedents of architecture that is valued by the peers both local and international. Master disciple relationships continue the values attitudes and approaches initiated by the celebrated; the master architects. International awards recognize them and celebrate their thoughts and ideas as the paradigms for others to follow. In a way, they create the spirit of theory of architecture and underpin the set of principles that the students of architecture would respectfully take as the given. For example in awarding the Gold medal 
to Charles Correa, UIA cited that award recognized "the exemplary nature of his life's work, in homage to his artistic insightand his human qualities that are an integral part of his architecture" (UIA Gold Medal citation 1990)

Similar or more powerful references to the works of celebrated architecture based on 'artistic principles' are commonplace. For example, in an article published in the New York Times in November 1989, Architecture critic Paul Goldberger wrote of Frank Gehry's work : His buildings are powerful essays in geometric form and materials and from an aesthetic standpoint, they are among the most profound and brilliant works of architecture of our time".

Frank Gehry says, "Architecture must solve complex problems. We must understand and use technology, we must create buildings which are safe and dry respectful of context and neighbours and face all the myriad of issues of social responsibility and even please the client. But then what? The moment of truth, the composition of elements, the selection of forms, scale, materials, colour. Finally, all the same issues facing the painter and the sculptor. Architecture is surely an art." (Acceptance Speech, Pritzker Prize)

We may go on looking at many other celebrated architects. Loui Barragan says "I believe that architects should design gardens to be used as much as the houses they build, to develop a sense of beauty and the taste and inclination towards the fine arts and other spiritual values" In his acceptance speech of the Pritzker prize he said, "It is impossible to understand art and the glory of its history without avowing religious spirituality and the mythical roots that lead us to the very reason of being of the artistic phenomenon"

Undenibaly, 'Architecture as an art ' remains center stage in the celebrated and valued works of architecture. Theory of Architecture that underpins the actual practice has shown no vacillation even in the midst of the growing knowledge of research generated by EnvironmentBehaviour research. Indeed, theory of architecture does take on board the 'concerns of people'; the social dimensions and as it used to be, and still claims to produce architecture employing 'humanistic concerns' as its central value base, while pursuing 'architecture as an art' paradigm.

If we return to the celebrated architects again for this reference; it is clear that there is an overwhelming reference to the human emotions and feelings as a precurser to all 'artistic activity'. Indeed Architecture although positions itself in the sphere of art seem to immerse itself in the 'mythical realm of feeling as the basis for the exploration of form". As Frank Gehry claimed "a response to context and appropriateness of feeling and spirit." Hallmarks of Gehry's work are his populist approach: He has a particular concern for the ways people move through and live and work comfortably in the spaces he has created. He insists that buildings address the context and culture of their sites. Gehry articulates his approach, when he says, "I approach each building as a sculptural object, a spatial container, a space with light and air, a response to context and appropriateness of feeling and splrit. To this container, this sculpture, the user brings his baggage, his program, and interacts with it to accommodate his needs. If he can't do that I have falled"

Thus it is not possible to accuse that celebrated architects do not care about 'social dimensions'. Indeed they do so implicitly; not by the employment of environment-behaviour research findings but by the application of what may be called an 'intellectual insight' and 'emotional and spiritual empathy' created between the architect and the people, through the medium of Architecture. Very much like in Art.

However, thirty years later, what Rapoport wrote in 1970 seems still valid and unchanged. Hopeful that environment-behaviour research will soon transform aesthetically biased design practice to a science based industrial design form, he wrote that "the new developments are not yet fully operational and their impact in both teaching and design has been slight. At the same time, there is more material and suggestive directions of development than have been used. Visual or more correctly, pictorial considerations continue to dominate the basic decisions within the economic, legal, physical, and social constraints which continue to operate. As a reaction to the pictorial approach, structure and technology have been assigned a major form-giving role in much design theory. This continues to neglect the psychological and socio-cultural determinants of space organization".

\section{Concluding Remarks}

This paper examined the emergence of the new field of environment-behavior research in responses to the lack of the specificity in dealing with humanistic issues in the design disciplines despite their claims in designing for people. It presented the way in which environmentbehaviour research has diversified to examine a broader spectrum of issues and how its theoretical base has progressed to examine facets of people, environments and their interface. Most notable concepts and issues that have gained focus of research and the methodologies adopted for examining those issues were presented. It was noted that despite a vast body of knowledge created and available, actual design practice seems to have benefited very little from these developments. Architectural practices on the contrary rely upon the personal understanding and intuitive processes as the basis for the conception, creation and evaluation of environments. It drew attentions to the fact that works of architecture are celebrated on the basis of valued poetics of space; the employment of aesthetics theory rather than man environment fit; the environment-behaviour theories. 
It is argued that environment-behaviour research has to become more relevant to the practice of architecture and that the bi-polarity that exists between practice and research must be minimized. However it does not suggest that the practice of architecture must give up its indulgence in the creation of poetic spaces and its aesthetic theory base. Indeed there is ample evidence that purely "functional" positivistic and mechanically contrived tight-fit designs having failed to generate the cherishability of space that is so essential for elevating quality of life and space. In a similar way, some celebrated works of architecture have failed to respond to specific social and psychological demands made upon such buildings. A fine balance between the poetics of space and a people-environment fit have to be sought to enable the construction of a 'theory of architecture' that is supported by environment-behaviour research as mush as intuition; the process the practicing architects are unlikely to abandon.

\section{References:}

Alexander, C (1964) Notes on the Synthesis of Form. Cambridge: Harvard University Press.

Alexander, C (1977) A Pattern Language. New York: Oxford University Press.

Broady, M (1968) Planning for People: Essays on the Social Context of Planning, London: Bedford Square press.

Canter, D (1977) Psychology of Place, London; - Architectural Press.

Canter,"D (1972) Psychology for Architects. London: Applied Science.

Canter, D (1985) Applying Psychology, the Inaugural Lecture at Department of Psychology. University of Surrey.

Ganiastas, V (1991) Design Theory and Architectural Practice: Architectural Hermeneutics; A Search for meaning in Architecture.

Hamdi, N (1992) Housing Withouit Houses, participation Flexibility Enablement. New York: Van Nostrand Reinhold.

Hertzberger, H (1991) Lessons for Students of Architecture, Rotterdam: Uitgeverij 010 publishers.

Kralk, (1970) Environmental Psychology, in, New Directions in Psychology. New York: Holt.

Lang, J (1974) Designing for Human Behaviour: Architecture and the Behavioural Sciences, Community Development series, Stroudsberg. Pensylvania. Dowdon Hutchinson and Ross Inc.

Lang (1987) Creating Architectural Theory, The Role of Behavioural Sciences in Environmental Research Now York: Van Nostrand Reinhold.

Lawson, B (1980) How Designers Think: The Design Process Demystified.London.
Jones, C (1974) Design Methods. London: Wiley.

MacEvan, M (1974) Crisis in Architecture. London : RIBA Publications Ltd.

Mitchell, H (1974) Professional and Client: An Emerging Collaborative Relationship, in, Lang (eds) Designing for Human Behaviour: Architecture and the Behavioural Sciences, Community Development series,Stroudsberg, Pensylvania. Dowdon Hutchinson and Ross Inc.

Mikellides, B (1980) Architecture for People.London: Studio Vista.

Montgomery, (1977) Introduction, in, Lars Lerup ed. (1977) Building the Unfinished. Architecture and Human Action,. London: Sage Publications, Sage Library of Social Research.

Nammuni, D (1991a)Teaching of Architectural Design A Moratuwa Experiment part 1 in SLA Architect 100 (7) 21.

Nammuni, D (1991b) Christopher Alexander and Design Methodology in Architecture Teaching of Architectural Design A Moratuwa Experiment part 1 in SLIA: SLA Architect 100 (8) 21.

Nammuni, D (1991c) From Learning to Teaching Architecture Teaching of Architectural Design A Moratuwa Experiment part 1 in SLA Architect 100 (9): 23.

Nammuni, D (1991d) Design Teaching at Moratuwa. Teaching of Architectural Design A Moratuwa Experiment part 1 in SLA Architect 100 (10) 15.

Nammuni, D (1992) Moratuwa Experiment as a Response to Teaching Architectural Design A Moratuwa Experiment part 1 in SLA Architect $100(11) 47$

Perin, (1974) With Man in Mind, Cambridge: MIT Press.

Pfeiffer, T. S (19) Behaviour and Interaction in BuiltSpace, Built Environment, Vol. 6 No. 1

Porteous, D (1977) Environment and Behaviour. Planning in an Everyday Urban Life. New York: Addison Welsey.

Rapoport, A (19) Development, Culture Change and Supportive Design, Habitat International, Vol. 7 No.5/6.

Rapoport, A (1981) Meaning of the Built-Environment: A Non Werbal Communication Approach. London: Sage Publications.

Rapoport, A (1990), in, Kent S (ed), Systems of Activities and Systems of Settings in Domestic Architecture and the Use of Space,Cambridge: Cambridge University Press.

Rapoport, A (1994) Introduction in Thirty Three Papers in Environment-Behaviour Research, Newcastle upon Tyne: Urban International Press.

\section{(Footnotes)}

' The term Environment-Behaviour in this paper refers in general sense to the numerous fields that examine the Man-Environment interface. The writer is aware of the distinctions between Environmental Psychology, Environment-Behaviour Research, Social Geography etc. but since the term environment-behaviour is employed more closely to the field of architecture, this term is employed in this paper for convenience of communication and understanding. ${ }^{2}$ EDRA: Environment Design Research Association (America), IAPS: International Association for the study of People and their Physical Settings (Europe) MERA: Man-Environment Research Association (Japan) and PAPER: People And Physical Environment Research Organisation (Australia and New Zealand). 